\title{
Neuroprotective Effect of Brasicca Olarecae L. Var. Botrytis (Brassicaceae) Flowers Extract on Memory Deficit in Aged \& Young Rats
}

\author{
Sonu Bhidwaria and Vrish Dhwaj Ashwlayan* \\ Department of Pharmaceutical Technology, India.
}

Submission: July 21, 2017; Published: October 16, 2017

*Corresponding author: Vrish Dhwaj Ashwlayan, Department of Pharmaceutical Technology, Meerut Institute of Engineering and Technology (M. I. E. T.), NH-58, Baghpat Crossing Bypass Road, Meerut-250005, Uttar Pradesh, India, Tel: 91-9412493228, Fax : 91-121-2439058,

E-mail:vrishsps@gmail.com

\begin{abstract}
Ageing deteriorates memory, retention and recall in human beings and is associated with marked structural and neuro-chemical changes in the brain. The serotonin neurons in the hippocampus regulate memory. Low serotonin level is responsible for difficulty in making decision. Loss of the acetylcholine, neurotransmitter in the brain of patient with Alzheimer's diseases appears to be a critical element to produce senile dementia. Senile dementia is a clinical syndrome affecting the elder persons with loss of memory and cognition. Serotonin and acetylcholine, key neurotransmitters are made from respectively tryptophan and choline which are found in Brassica oleracea L. var. botrytis (cauliflower) vegetable also improve memory in people with Alzheimer's disease.

High levels of tryptophan in the brain directly influence increased serotonin production and new brain cell production begins to rise. The chloroform-metabolic extract of Brassica oleracea L. var. botrytis (СMEBOB) flowers was investigated for its neuroprotective effect against ageing related and scopolamine induced memory deficits in aged and young rats respectively using elevated plus maze and Morris water maze. 2000 and $3000 \mathrm{mg} / \mathrm{kg}$, p.o. doses of the extract were administered for four consecutive days. Oxidative stress biomarkers (elevated brain malondialdehyde, nitrite and lower reduced glutathione levels) in cognitive impairment of rats were significantly reversed by the flowers extract. Chronic consumption of CMEBOB extract $(3000 \mathrm{mg} / \mathrm{kg}$, p.o.) significantly improved performance of both mazes in aged rats and scopolamine treated young rats by its potent cholinomimatic action, anti-oxidative action and could be useful in management of memory impairment associated with neurodegenerative diseases.
\end{abstract}

Keywords: Brassica; memory deficits; ageing; cauliflower; serotonin; acetylcholine; anti-cholinesterase; dementia

Abbreviations: AChE: Acetyl cholinesterase; Anti-ChE: Anti cholinesterase; BP: Boiling Point; CPCSEA: Committee for the Purpose of Control and Supervision of Experiment on Animal; DTNB:5, 5'-Dithio-bis 2- Nitro Benzoic Acid; ELT: Escape Latency Time; EPM: Elevated Plus Maze; GSH: Reduced Glutathione; CMEBOB: Chloroform-Methanolic Flowers Extract of Brassica oleracea L. var. botrytis; IR: Inflation Ratio; IVRI: Indian Veterinary Research Institute; MDA: Malondialdehyde; MWM: Morris Water Maze; NO: Nitric Oxide; Rpm: Round per minute; ROS: Reactive Oxygen Species;TBA: Thiobarbituric acid; TCA: Trichloro Acetic Acid; TLT: Transfer Latency Time; TSTQ: Time Spent in Target Quadrant

\section{Introduction}

Learning is defined as acquisition of information and skills. Subsequent retention of this information is called as memory. Any disturbance in dhi (process of learning), dhuti (process of retention) and smriti (process of recall) in Ayurveda results in the loss of cognitive ability [1]. Dementia, an organic disorder refers to several pathological states of brain, leading to disruption of personality and multiple higher cortical functions including memory, reasoning, orientation, comprehension, learning capacity and emotional stability [2]. It is therefore not a normal result of ageing, but rather pathological conditions [3] such as Alzheimer's disease, Pick's disease, cerebrovascular disease, hypoxic and ischemic encephalopathy, Parkinson's disease, alcoholism, drug abuse, brain tumor and infections like HIV and syphilis [4].

Vascular dementia is similar to senile dementia but memory is less affected, mood fluctuations more prominent; physical frailty, stepwise onset. Stroke-related dementia occurs when parts of the brain become damaged following a stroke. A stroke 
occurs when blood supply to a part of the brain is suddenly cut off. This may cause difficulties in moving, problems with coordination, speech and sight depending on the part of the brain affected. If a stroke causes memory loss and problems with attention, then a person may be diagnosed with post-stroke dementia. Similar damage can also be caused by small strokes in the brain (which may be called transient ischemic attacks), multi-infarct dementia may be too small for a person to notice [5]. Marked fluctuation in cognitive ability; visual hallucinations; Parkinsonism are symptoms of Levy body dementia.

Personality changes; mood changes; disinhibition; language difficulties are symptoms of fronto-temporal dementia. The elder patient with Parkinson's disease characterized by rigidity, tremor, bradykinesia, and hypokinesia with secondary manifestations like expression less face, defective posture \& shuffling gait due to degeneration of neurons in nigrostriatal dopaminergic tract and excessive secretion of saliva (sialorrhoea) and front temporal dementia due to increased cholinergic transmission, is more susceptible to the adverse effects (postural hypotension, ventricular dysrhythmias and psychiatric effects) of levodopa [6]. Prevalence rate of senile, vascular, lewy body and Frontotemporal dementia is 50 to $70 \%, 20$ to $30 \%,<5 \%$ and 5 to $10 \%$ respectively. The overall prevalence of late onset dementia is 7.1 per cent for people over 65. Today's memory impairment is major problem due to dementia in elder people.Ageing is a spiritual and psychological journey as well as a physical one. Ageing is commonly characterized by a progressive, generalized impairment of physiochemical and biological aspects of cellular body functions for an increasing vulnerability to environmental challenges and a growing risk of disease, long-term morbidity and potentially mortality [7]. As cells mature, they naturally stop dividing and enter into a period called cellular senescence. In response to DNA damage (shortened telomeres) cells either senescence or self-destruct (apoptosis), if the damage cannot be repaired. The concentration of oxidative damage proteins, lipids and DNA molecules increase in disease with the human ageing [8].

Ageing deteriorates memory, retention and recall in human beings and is associated with marked structural and neuro-chemical changes in the brain. The activity of choline acetyltransferase, a marker enzyme of acetylcholine, is reduced in neocortex due to accumulation of neurotoxin amyloidal beta protein and hippocampus due to formation of neurofibrillary tangles and consequently results in senile dementia. Senile dementia is a clinical syndrome affecting the elder persons with loss of memory and cognition $[9,10]$. Loss of the acetylcholine (ACh), neurotransmitter in the brain of patient with Alzheimer's disease appears to be a critical element to produce senile dementia.

ACh is synthesized in nerve terminals from acetyl coenzyme A and choline, and the reaction is catalyzed by choline acetyltransferase (ChAT). Scopolamine, a centrally muscarinic cholinergic receptor antagonist causes memory impairment along with reduced cerebral blood flow, increased acetylcholinestrase (AChE) activity and oxidative stress in rats and human's brain [11]. People diagnosed with amnesic MCI have an increased risk of developing dementia, but only about 1 in 6 eventually do. Functional memory problems: names of people, places; misplacing things; keeping track of schedule of commitments; forgetting to carry out an intended activity; numbers \& passwords and remembering what was said or decided upon are commonly-known features of normal cognitive ageing, and also of mild cognitive impairment (MCI).

Its symptoms get worse with time. Amnestic' MCI is characterized by a set of problems with working memory, planning, language, and/or attention which decline more rapidly than they would in normal, age-related cognitive decline, but not to the extent that they interfere with a person's dayto-day life. Despite recent advances in our understanding of the pathophysiology of dementia, current treatments for these disorders often fall short of expectation. Patients, family members and caregivers often find themselves unable to resist the lure of using so-called natural products and dietary supplements as possible sources of new treatments to treat or prevent memory impairments and their behavioural and psychological symptoms [12].

Herbal medicines offer therapeutics for age-related disorder like memory loss [13]. Catechin and gallic acid from Sanguisorbae radix, epicatchin and 3, 4 dihydroxy benzoic acid from Smilax rhizoma are A $\beta$ induced neurotoxicity inhibitors [14]. Therefore, it seems worthwhile to explore the utility of traditional medicines for the treatment of various cognitive disorders. The plants in Brassicacaeae family all share a common feature: their four-petaled flowers resemble to a Greek cross and are often referred to as crucifers or cruciferous vegetables.

This is a biennial and frost tolerant vegetable with compact heads of immature or aborted flowers contracted into a single white head. Brassica oleracea L. var. botrytis (cauliflower) family: Brassicacaeae has traditionally been found to boost memory in people with senile dementia. The name cauliflower comes from the Latin words caulis, meaning-stalk, and floris, meaning-flowers as suggested by its name; cauliflower is actually a flower [15]. Cauliflower is also an out-breeding plant. In addition, cauliflower must undergo vernalization in order to flowers. In some regions where winter temperature does not drop below 28F, brassicas can be planted, and seed is harvested the following summer.

Mostly, cauliflower is self- incompatible. Cauliflower rich in $27 \mathrm{mg} / 100 \mathrm{~g}$ tryptophan [16], indole-3-carbinol, vitamin B6, tocopherols, ascorbic acid, beta-carotene, kaempferol, quercetin, rutin, glycosides, fatty acid, cellulose, volatile oil, steroids, napthoquinone, vitamin- $K$, poly-phenols, cinnamic acid, sulforaphane and choline, the key ingredients make 
cauliflower such a powerful brain food. The allicin in cauliflower reduces the risk of strokes and improves the health of the heart. Selenium and vitamin-C work together to boost the immune system. The Indian home remedy of cauliflower is also used to treat inflammation, digestion, cardiovascular diseases, diabetes, neurodegenerative disorders, and various forms of cancers.

Choline intake during pregnancy "super-charged" the brain activity of animals in utero, indicating that it may boost cognitive function, and improve learning and memory. It may even diminish age-related memory decline and brain's vulnerability to toxins during childhood, as well as conferring protection later in life. The serotonin neurons in the hippocampus regulate memory and mood. Low serotonin level is responsible for difficulty in making decision. High levels of tryptophan in the brain directly influence increased serotonin production and new brain cell production begins to rise [17]. Tryptophan is the chemical precursor of serotonin and producing more serotonin through dietary means is more complicated than eating tryptophan-rich foods.

Vitamin B6 is needed to convert tryptophan to serotonin. ACh and serotonin, key neurotransmitters are made from respectively choline and tryptophan which are found in cauliflower vegetable also seem to improve memory in people with Alzheimer's disease. Therefore, the aim and objective of present research work is to investigate neuroprotective effect of Brassica oleracea L. var. botrytis flowers using interceptive (age related and scopolamine induced memory deficits) and exteroceptive (elevated plus maze and Morris water maze) behavioural models in young and aged rats and provide scientific basis for the same.

\section{Materials and Methods}

The experimental protocol was approved by the institutional animal ethics committee no.711/PO/Re/S/02/CPCSEA) and experiments were conducted according to the Committee for the purpose of control and supervision of experiment on animal (CPCSEA) guidelines on the use and care of experimental animals.

\section{Plant material}

The flowers of Brassicaoleracea L. var. botrytis was purchased from market. The flowers were authenticated by Dr. R. S. Saxena Reader and Head, Botany Department, Meerut College, Meerut. A voucher specimen was deposited for the plant in the same herbarium.

\section{Extraction}

Air dried flowers (20gm) of Brassica oleracea L. var. botrytis were coarsely powered and extracted with petroleum ether (B.P. $40-60{ }^{\circ} \mathrm{C}$ ) for defatting of crude drug followed by chloroform: methanol (2:1) solvents by continuous hot percolation method using "Sox let apparatus"[18]. This was repeated thrice with fresh solvent each time. The extracts from all the three washes were pooled and concentrated using Rota-evaporator (Per fit) to obtain dark viscous mass. The residue was then dried at room temperature. The per cent yield of petroleum ether and the chloroform-methanol flowers extract was found to be 3.45 and 10 respectively. The extract was suspended in normal saline ( $0.9 \% \mathrm{w} / \mathrm{v}$ sodium chloride solution).

\section{Drugs and chemicals}

Piracetam and scopolamine hydro bromide drugs were purchased from Sigma Aldrich. Analytical reagent grade chemicals namely petroleum ether, methanol, acetyl thiocholine iodide, 5,5-dithiobis-2-nitrobenzoic acid (DTNB), trichloroacetic acid (TCA), triphenyltetrazolium chloride (TTC), thiobarbituric acid (TBA) were purchased from Fisher scientific.

\section{Experimental Animals}

Swiss albino rats of 30 months age $(250+2 g)$ and young rats of 6 weeks age $(35+2 \mathrm{~g})$ were procured from Indian Veterinary Research Institute (IVRI), Izzatnagar, Bareilly (Uttar Pradesh) India. They were placed in animal house provided with 12 hours light and dark cycles at $25+2{ }^{\circ} \mathrm{C}$ and had free access to water and standard laboratory diet. Experiments were carried out between 09:00 and 17:00 hours. Efforts were made to minimize animal suffering and number of animals used.

\section{Locomotors Activity Measurement by rota-rod}

The rota-rod test is used to assess motor-coordination and balance in rodents. The ability of the rat to hold on to the horizontally rotating rod (diameter $2.5 \mathrm{~cm}, 4$ rotations per minutes) was used to assess motor co-ordination [19]. Rat has to keep its balance on a rotating rod. It is measured the time (latency) taken by rat to fall off from the rotating rod. Latency at which each rat falls off the rod at different speeds from 4 to $40 \mathrm{rpm}$ in $300 \mathrm{sec}$ was recorded. If a rat was climbing on the rod completed rotation and latency recorded. Rats which demonstrated impairment of muscle coordination with or without drug treatment were not included in the study. $15 \%$ exclusion rate was noted.

\section{Assessment of Neuro-protective effect}

\section{Interceptive behavioral models}

Age-related memory deficits: An aged (30 months old) rat model for no tropic activity provides a natural model of ageing and cognitive decline and may be more translatable to humanscompared to other models which focus only on one particular aspect of the disease. Sensory perception becomes impaired with advancing age [20]. The aged rat expands the portfolio of options; drug developers have to study no tropic activity, getting us one step closer to discovering a cure.

\section{Scopolamine-induced memory deficits}

Scopolamine $(0.3 \mathrm{mg} / \mathrm{kg}$, i.p.) is a central muscarinic receptor antagonist with memory deficits properties that have been used for decades in experimental young rats to induce impairment in 
their performance of a variety of tasks requiring intact working and reference memory [21].

\section{Exteroceptive Behavioral Models}

\section{Elevated plus maze apparatus}

Elevated plus-maze serves as the exteroceptive behavioral model to evaluate acquisition and retention of memory in rats [22]. The elevated plus maze for rats consists of two open arms $(50 \mathrm{~cm} \times 10 \mathrm{~cm})$ and two covered arms $(50 \mathrm{~cm} \times 10 \mathrm{~cm} \times 40 \mathrm{~cm})$ which are extended from a central platform $(10 \mathrm{~cm} \times 10 \mathrm{~cm})$ and elevated to a height $50 \mathrm{~cm}$ from the floor. Acquisition of memory was recorded on day 4 after scopolamine administration. On the first day, each rat is placed at the end of an open arm, facing away from the central platform. Time taken by the rat to move into any one of the covered arms with all its four legs is recorded as TLT on the first day (i.e., day 4 of drug administration) for each animal. If the rats do not enter into one of the covered arms within 90 seconds, they are gently pushed into one of the two covered arms and the TLT is assigned as 90 seconds. The rat was allowed to explore the maze for $10 \mathrm{sec}$ and then return to its home cage. Memory retention was calculated after $24 \mathrm{hrs}$ of acquisition trial (on the day 5) as inflation ratio using the following formula:

$$
\text { Inflation ratio (IR) }=\mathrm{L}_{1}-\mathrm{L}_{0} / \mathrm{L}_{0}
$$

Where, $\mathrm{L}_{0}$ is initial TLT on day 4 in seconds and L1 is the TLT after 24 hrs (day 5) of acquisition trial [23].

\section{Morris water maze}

Morris water maze was employed to evaluate learning and memory [24]. It consists of a circular water tank (diameter $150 \mathrm{~cm}$ and height $45 \mathrm{~cm}$ ), filled with water maintained at 25 ${ }^{\circ} \mathrm{C}$. The water is made opaque with a white coloured dye. The tank is divided into four equal quadrants with the help of two Experimental Protocol

Table 1: Effect of CMEBOB on ELT during acquisition trials in scopolamine induced memory deficits. Control: I; Negative Control Group: II, III; Positive Control Group: VI to XV; Curative IV, V.

\begin{tabular}{|c|c|c|c|c|c|c|}
\hline Group & Treatment & Dose $\left(\mathrm{kg}^{-1}\right)$ & Day 1 & Day 2 & Day 3 & Day 4 \\
\hline I & Control Group $(0.9 \% \mathrm{NaCl})$ & $10 \mathrm{ml}$ & $108.63 \pm 6.65$ & $91.88 \pm 16.24^{\mathrm{a}}$ & $63.17 \pm 15.25^{\mathrm{a}}$ & $40.63 \pm 15.08^{\mathrm{a}}$ \\
\hline II & Scopolamine in young rats & $0.3 \mathrm{mg}$ & $114.29 \pm 3.82^{\mathrm{b}}$ & $111.40 \pm 3.16^{\mathrm{b}}$ & $96.50 \pm 12.02^{\mathrm{b}}$ & $89.13 \pm 9.89^{b}$ \\
\hline III & Ageing $(0.9 \% \mathrm{NaCl})$ & $10 \mathrm{ml}$ & $120 \pm 00^{b}$ & $105 \pm 1.41^{b}$ & $90 \pm 0.70^{\mathrm{b}}$ & $85 \pm 0.52^{b}$ \\
\hline IV & Piracetam- Per se treated young rats & $200 \mathrm{mg}$ & $101.84 \pm 10.50$ & $62.10 \pm 7.91$ & $36.84 \pm 8.81$ & $16.50 \pm 4.37$ \\
\hline $\mathbf{V}$ & Piracetam-Per se treated aged rats) & 200 mg, i.p. & $45.67 \pm 10.75^{b}$ & $37.50 \pm 9^{b}$ & $26.32 \pm 4.5^{b}$ & $14 \pm 3.08^{b}$ \\
\hline VI & CMEBOB - Per se in young rats & $2000 \mathrm{mg}$, p.o. & $88.63 \pm 10.18^{b}$ & $49.59 \pm 12.71^{\mathrm{b}}$ & $34 \pm 6^{\mathrm{b}}$ & $17.26 \pm 2.28^{b}$ \\
\hline VII & CMEBOB Extract-Per se in aged rats & 2000mg, p.o. & $34.88 \pm 4.5^{b}$ & $32.88 \pm 4.09^{b}$ & $30.75 \pm 8.79^{b}$ & $21.50 \pm 7.10^{b}$ \\
\hline VIII & CMEBOB extract-Per se treated young rats & 3000mg, p.o. & $94.55 \pm 10.69^{\mathrm{b}}$ & $57.71 \pm 16.71^{\mathrm{b}}$ & $41.63 \pm 9.03^{\mathrm{b}}$ & $15.05 \pm 4.02^{\mathrm{b}}$ \\
\hline IX & CMEBOB-Per se extract treated aged rats & $\begin{array}{l}3000 \mathrm{mg} / \mathrm{Kg} \\
\text { p.o. }\end{array}$ & $33.57 \pm 6.03^{b}$ & $28.69 \pm 3.69^{b}$ & $28 \pm 2.03^{b}$ & $26.82 \pm 7.79^{b}$ \\
\hline $\mathbf{X}$ & Piracetam+ scopolamine treated Young rats & $\begin{array}{c}200+0.3 \mathrm{mg} \\
\text { p.o. }\end{array}$ & $33 \pm 6.25^{c}$ & $21.75 \pm 4.82^{c}$ & $14.93 \pm 5.49^{c}$ & $10 \pm 2.31^{\mathrm{c}}$ \\
\hline $\mathbf{X I}$ & Piracetam+ scopolamine treated aged rats & $\begin{array}{c}200+0.3 \mathrm{mg} \\
\text { p.o. }\end{array}$ & $50 \pm 2.21^{\mathrm{c}, \mathrm{d}}$ & $23 \pm 3.31^{\mathrm{c}, \mathrm{d}}$ & $19.44 \pm 3.09^{c, d}$ & $15.44 \pm 1.09^{\mathrm{c}, \mathrm{d}}$ \\
\hline
\end{tabular}

threads, fixed at right angle to each other on the rim of the pool. A platform $(10 \mathrm{~cm} 2)$ of $29 \mathrm{~cm}$ height is located in the centre of one of these four quadrants. The position of platform and clues were kept consistent throughout the training session. In the present study, target quadrant was Q1.

Acquisition trials: Each rat was subjected to four consecutive trials on each day with an interval of five minutes, during which the rat was allowed to escape on the hidden platform and was allowed to remain there for $20 \mathrm{sec}$. In case of the inability of rat to locate the hidden platform within 120 seconds, it was gently guided by hand to the platform and allowed to remain there for 20sec. Escape latency time (ELT) to locate the hidden platform in water maze was noted as an index of acquisition and learning. In preliminary study, trials were conducted to familiarize the rat with the task and these trials were not counted. The rat was subjected to acquisition trials for four consecutive days. The starting position on each day to conduct four acquisition trials was changed as follows:

$\begin{array}{lllll}\text { Day 1 } & \text { Q1 } & \text { Q2 } & \text { Q3 } & \text { Q4 } \\ \text { Day 2 } & \text { Q2 } & \text { Q3 } & \text { Q4 } & \text { Q1 } \\ \text { Day 3 } & \text { Q3 } & \text { Q4 } & \text { Q1 } & \text { Q2 } \\ \text { Day 4 } & \text { Q4 } & \text { Q1 } & \text { Q2 } & \text { Q3 }\end{array}$

Retrieval trial: On the next day, platform was removed and each rat was allowed to explore the pool for $120 \mathrm{sec}$. Mean time spent by rat in each of four quadrants was noted. The mean time spent by the rat in target quadrant (Q4) for searching the hidden platform was noted as an index of retrieval. The experimenter always stood at the same position. Care was taken that relative location of water maze with respect to other objects in the laboratory, serving as prominent visual clues was not disturbed during the total duration of study. 


\section{Global Journal of Pharmacy \& Pharmaceutical Sciences}

\begin{tabular}{|c|c|c|c|c|c|c|}
\hline XII & $\begin{array}{c}\text { CMEBOB Extract (L) + Scopolamine treated } \\
\text { Young rats }\end{array}$ & $\begin{array}{c}2000 \mathrm{mg}+0.3 \\
\mathrm{mg}, \mathrm{p} .0 .\end{array}$ & $67.37 \pm 20^{\mathrm{c}}$ & $61.69 \pm 9.19^{\mathrm{c}}$ & $55 \pm 8.35^{\mathrm{c}}$ & $27.44 \pm 8.85^{\mathrm{c}}$ \\
\hline $\mathbf{X I I I}$ & $\begin{array}{c}\text { CMEBOB Extract (L) + Scopolamine treated } \\
\text { aged rats }\end{array}$ & $\begin{array}{c}2000 \mathrm{~m}+0.3 \mathrm{mg} \\
\text { p.o. }\end{array}$ & $79 \pm 1.79^{\mathrm{c}, \mathrm{d}}$ & $68 \pm 3.75^{\mathrm{c}, \mathrm{d}}$ & $40 \pm 3.44^{\mathrm{c}, \mathrm{d}}$ & $25 \pm 11^{\mathrm{c}, \mathrm{d}}$ \\
\hline $\mathbf{X I V}$ & $\begin{array}{c}\text { CMEBOB Extract (H) + Scopolamine treated } \\
\text { Young rats }\end{array}$ & $\begin{array}{c}3000 \mathrm{mg}+0.3 \\
\mathrm{mg} \text { p.o. }\end{array}$ & $48.06 \pm 14.92^{\mathrm{c}}$ & $38.26 \pm 5.75^{\mathrm{c}}$ & $30.57 \pm 5.92^{\mathrm{c}}$ & $18.19 \pm 3.99^{\mathrm{c}}$ \\
\hline $\mathbf{X V}$ & $\begin{array}{c}\text { CMEBOB Extract (H) + Scopolamine treated } \\
\text { Aged rats }\end{array}$ & $\begin{array}{c}3000 \mathrm{mg}+0.3 \\
\text { mg p.o. }\end{array}$ & $73.50 \pm 14.24^{\mathrm{c}, \mathrm{d}}$ & $50 \pm 2.11^{\mathrm{c}, \mathrm{d}}$ & $31 \pm 3.55^{\mathrm{c}, \mathrm{d}}$ & $28.15 \pm 4.59^{\mathrm{c}, \mathrm{d}}$ \\
\hline
\end{tabular}

Table 2: Effect of chloroform: methanolic extract of Brassica oleracea flowers on ageing and scopolamine induced decrease in time spent in target quadrant during retrieval trial.

\begin{tabular}{|c|c|c|c|}
\hline Group & Treatment & Dose $\mathbf{k g}^{-1}$ ) & Time Spent in Target Quadrant (Q1) \\
\hline I & Control Group $(0.9 \%$ NaCl) & $10 \mathrm{ml}$ & $50.41 \pm 4.89$ \\
\hline II & Scopolamine in young rats & $0.3 \mathrm{mg}$ & $31 \pm 2.10^{\mathrm{a}}$ \\
\hline III & Ageing $(0.9 \% \mathrm{NaCl})$ & $10 \mathrm{ml}$ & $31.37 \pm 3.48^{\mathrm{a}}$ \\
\hline IV & Piracetam-Per se treated young rats & $200 \mathrm{mg}$ & $74 \pm 5.16^{\mathrm{a}}$ \\
\hline V & Piracetam-Per se treated aged rats & $200 \mathrm{mg}$, i.p. & $72 \pm 8.22^{\mathrm{c}}$ \\
\hline VI & CMEBOB-Per se in young rats & $2000 \mathrm{mg}$, p.o. & $66 \pm 3.90^{\mathrm{a}}$ \\
\hline VII & CMEBOB Extract-Per se in aged rats & $2000 \mathrm{mg}$, p.o. & $51.83 \pm 2.70^{\mathrm{c}}$ \\
\hline VIII & CMEBOB extract-Per se treated young rats & $3000 \mathrm{mg}$, p.o. & $69 \pm 3.93^{\mathrm{a}}$ \\
\hline IX & CMEBOB-Per se extract treated aged rats & $3000 \mathrm{mg} / \mathrm{Kg}$ p.o. & $63 \pm 4.81^{\mathrm{d}}$ \\
\hline X & Piracetam+ scopolamine treated Young rats & $200+0.3 \mathrm{mg}$, p.o. & $49.5 \pm 4.68^{\mathrm{b}}$ \\
\hline XI & Piracetam+ scopolamine treated aged rats & $200+0.3 \mathrm{mg}$, p.o. & $59 \pm 4.07^{\mathrm{b}, \mathrm{c}}$ \\
\hline XII & CMEBOB Extract (L) + Scopolamine treated Young rats & $2000 \mathrm{mg}+0.3 \mathrm{mg}$, p.o. & $61 \pm 6.51^{\mathrm{b}}$ \\
\hline XIII & CMEBOB Extract (L) + Scopolamine treated aged rats & $2000 \mathrm{mg}+0.3 \mathrm{mg}$, p.o. & $47 \pm 2.57^{\mathrm{b}, \mathrm{c}}$ \\
\hline XIV & CMEBOB Extract (H) + Scopolamine treated Young rats & $3000 \mathrm{mg}+0.3 \mathrm{mg}$, p.o. & $69 \pm 4.80^{\mathrm{b}}$ \\
\hline XV & CMEBOB Extract(H) + Scopolamine treated Aged rats & $3000 \mathrm{mg}+0.3 \mathrm{mg}$, p.o. & $55 \pm 3.56^{\mathrm{b}, \mathrm{c}}$ \\
\hline
\end{tabular}

Table 3: Effect of СМЕВОВ flowers extract on ageing related and scopolamine induced changes in Transfer latency time as Inflation ratio.

\begin{tabular}{|c|c|c|c|}
\hline Group & Treatment & Dose (kg-1) & Inflation ratio \\
\hline I & Control Group (0.9\% Na Cl) & $10 \mathrm{ml}$, i.p. & $0.085 \pm 0.013$ \\
\hline II & Scopolamine in young rats & $0.3 \mathrm{mg}$, i.p. & $0.021 \pm 0.008^{\mathrm{a}}$ \\
\hline III & Ageing (0.9\% NaCl) & $10 \mathrm{ml}$, p.o. & $0.018 \pm 0.005^{\mathrm{a}}$ \\
\hline IV & Piracetam- Per se treated young rats & $200 \mathrm{mg}$, p.o. & $0.82 \pm 0.09^{\mathrm{a}}$ \\
\hline V & Piracetam-Per se treated aged rats & $200 \mathrm{mg}$, i.p. & $0.59 \pm 0.031^{\mathrm{c}}$ \\
\hline VI & CMEBOB - (L) Per se in young rats & $2000 \mathrm{mg}$, p.o. & $0.318 \pm 0.21^{\mathrm{a}}$ \\
\hline VII & CMEBOB extract- (L) Per se in aged rats & $2000 \mathrm{mg}$, p.o. & $0.225 \pm 0.016$ \\
\hline VIII & CMEBOB extract - (H) Per se treated young rats & $3000 \mathrm{mg}$, p.o. & $0.41 \pm 0.069^{\mathrm{c}}$ \\
\hline IX & CMEBOB- (H) Per se extract treated aged rats & $3000 \mathrm{mg} / \mathrm{Kg}$ p.o. & $0.476 \pm 0.082^{\mathrm{c}}$ \\
\hline X & Piracetam+ scopolamine treated young rats & $200+0.3 \mathrm{mg}$, p.o. & $0.298 \pm 0.048^{\mathrm{b}}$ \\
\hline XI & Piracetam+ scopolamine treated aged rats & $200+0.3 \mathrm{mg}$, p.o. & $0.395 \pm 9.42^{\mathrm{b}}$ \\
\hline XII & CMEBOB Extract (L) + scopolamine treated young rats & $2000 \mathrm{mg}+0.3 \mathrm{mg}$, p.o. & $0.225 \pm 0.016^{\mathrm{b}}$ \\
\hline XIII & CMEBOB Extract (L) + Scopolamine treated aged rats & $2000 \mathrm{mg}+0.3 \mathrm{mg}$, p.o. & $0.318 \pm 0.034^{\mathrm{b}, \mathrm{c}}$ \\
\hline XIV & CMEBOB Extract (H) + scopolamine treated young rats & $3000 \mathrm{mg}+0.3 \mathrm{mg}$, p.o. & $0.228 \pm 0.014^{\mathrm{b}}$ \\
\hline XV & CMEBOB Extract (H) + scopolamine treated aged rats & $3000 \mathrm{mg}+0.3 \mathrm{mg}$, p.o. & $0.352 \pm 0.179 \mathrm{~b}{ }^{\mathrm{c}}$ \\
\hline
\end{tabular}

The rats were divided into fifteen groups (Table 1-4). Each group comprised of six animals.In group I (control) \& III, respectively normal rats and aged rats were administered 0.9 $\% \mathrm{w} / \mathrm{v}$ sodium chloride solution $(10 \mathrm{ml} / \mathrm{kg}$, i.p.) on day 1 and again after 24 hours i.e., on day 2 . In group II and IV, young rats were administered scopolamine hydro bromide $(0.3 \mathrm{mg} / \mathrm{kg}$, i.p.) and piracetam $(200 \mathrm{mg} / \mathrm{kg})$ respectively. TLT was recorded after 45 minutes in groups I, II \& III; after $60 \mathrm{~min}$. in group IV respectively and then after 24 hours i.e., on day 2) using EPM. In group VI and VIII of young rats, group VII and IX of aged rats were administered СMEBOB at doses of 2000 and $3000 \mathrm{mg} / \mathrm{kg}$, p.o. respectively for four consecutive days.

Table 4: Table showing the effect of Brassica oleracea L. var. botrytis on level of biochemical estimation. 
Global Journal of Pharmacy \& Pharmaceutical Sciences

\begin{tabular}{|c|c|c|c|c|c|c|c|c|}
\hline Groups & Treatments & Dose(Kg-1) & No & AChE & Catalase & GSH & MDA & SOD \\
\hline I & $\begin{array}{c}\text { Control }\{\text { Normal } \\
\text { saline }(0.9 \% \mathrm{Nacl})\}\end{array}$ & $10 \mathrm{ml}, \mathrm{ip}$ & 0.0900 & 0.0000035 & 0.314000 & 52.3900 & 91.2900 & 638.6600 \\
\hline II & $\begin{array}{c}\text { Ageing \{Normal } \\
\text { saline }(0.9 \% \mathrm{Nacl})\end{array}$ & $10 \mathrm{ml}, \mathrm{ip}$ & 0.0140 & 0.0000053 & 0.325000 & 42.1700 & 98.9900 & 185.0000 \\
\hline III & Scopolamine & $0.3 \mathrm{mg}$, i.p & 0.0008 & 0.0000079 & 0.390000 & 35.0600 & 148.2100 & 41.6000 \\
\hline IV & Piracetam & $200 \mathrm{mg}$, i.p. & 0.6 & $\begin{array}{l}3.600000 \\
e-007\end{array}$ & 0.048 & 120.73 & 29.79 & 2740.25 \\
\hline V & Aging+Piracetam & 200mg,i.p. & 0.5550 & $\begin{array}{c}4.900000 \\
\text { e- } 007\end{array}$ & 0.041600 & 114.7600 & 55.7300 & 3481.9300 \\
\hline VI & Extract & 2000mg,p.o & 0.3900 & 0.00000098 & 0.121000 & 85.2700 & 66.3600 & 1380.4000 \\
\hline VII & Extract & $3000 \mathrm{mg}, \mathrm{p.o}$ & 0.5400 & 0.0000013 & 0.164000 & 88.0300 & 70.2000 & 1256.7800 \\
\hline VIII & Aging+Extract & $2000 \mathrm{mg}$, p.o & 0.3800 & 0.00000079 & 0.071000 & 103.5900 & 64.4300 & 1421.6300 \\
\hline IX & Aging+Extract & 3000mg,p.o & 0.4200 & 0.00000098 & 0.085000 & 102.7600 & 65.4300 & 1339.1700 \\
\hline $\mathrm{x}$ & $\begin{array}{c}\text { Piracetam } \\
+ \text { Scopolamine }\end{array}$ & $\begin{array}{l}200+0.3 \mathrm{mg}, \\
\text { i.p. }\end{array}$ & 0.3700 & $\begin{array}{l}2.500000 \\
\text { e- } 007\end{array}$ & 0.172000 & 69.2800 & 82.7600 & 885.9100 \\
\hline XI & $\begin{array}{c}\text { Ageing+Piracetam } \\
\text { +Scopolamine }\end{array}$ & $\begin{array}{l}200+0.3 \mathrm{mg}, \\
\text { i.p. }\end{array}$ & 0.3800 & 0.0000015 & 0.184000 & 78.8200 & 97.1500 & 803.5100 \\
\hline XII & $\begin{array}{c}\text { Extract } \\
+ \text { Scopolamine }\end{array}$ & $\begin{array}{l}2000 \mathrm{mg} \text {, p.o } \\
+0.3 \mathrm{mg} \text {, i.p. }\end{array}$ & 0.1500 & 0.0000017 & 0.271000 & 68.1300 & 74.0500 & 721.6000 \\
\hline XIII & $\begin{array}{l}\text { Ageing + Extract } \\
\text { (L)+Scopolamine }\end{array}$ & $\begin{array}{l}2000 \mathrm{mg} \text {, p.o } \\
+0.3 \mathrm{mg} \text {, i.p. }\end{array}$ & 0.1700 & 0.0000025 & 0.283000 & 65.3400 & 77.5700 & 721.0000 \\
\hline $\mathrm{XV}$ & $\begin{array}{l}\text { Ageing+Extract }(\mathrm{H}) \\
+ \text { +Scopolamine }\end{array}$ & $\begin{array}{l}3000 \mathrm{mg}, \mathrm{p.o} \\
+0.3 \mathrm{mg} \text {, i.p }\end{array}$ & 0.3000 & $\begin{array}{l}2.500000 \\
\text { e- } 007\end{array}$ & 0.150000 & 80.4100 & 73.3800 & 779.2500 \\
\hline
\end{tabular}

In group VI to IX, TLT was recorded after 60 minutes on day 4 and then after 24 hours on day 5 using EPM. In groups X, XII, $\mathrm{XIV}$ of young rats and in groups XI, XIII and XV of aged rats were administered piracetam (200mg/kg, i.p.) and scopolamine hydro bromide (0.3mg/kg, i.p.); СMEBOB (2000 and $3000 \mathrm{mg} / \mathrm{kg}$, p.o.) and scopolamine hydro bromide $(0.3 \mathrm{mg} / \mathrm{kg}$, i.p.) respectively 60 and $45 \mathrm{~min}$. before the day 1 exposure on EPM. TLT was recorded on day 4 and then on day 5 in X to XV groups. Group I (control) \& III, normal saline solution $(10 \mathrm{ml} / \mathrm{kg}$, i.p.) treated respectively normal and aged rats was subjected to MWM for measuring ELT (from day 1 to day 4) and TSTQ on the day 5. In group II \& IV, young rats were administered scopolamine hydro bromide $(0.3 \mathrm{mg} / \mathrm{kg}$, i.p.) and piracetam $(400 \mathrm{mg} / \mathrm{kg}$, i.p.) respectively before 45 minutes of acquisition trials conducted on four consecutive days (from day 1 to day 4). In case of VI and VIII, young rats, group VII and IX, aged rats, CMEBOB at doses of 2000 and $3000 \mathrm{mg} / \mathrm{kg}$, p.o., respectively were administered for four days before 60 minutes of acquisition trials conducted on four consecutive days (from day 1 to day 4).

In groups X, XII, XIV, young rats, in groups XI, XIII and XV, aged rats were administered, CMEBOB (2000 and $3000 \mathrm{mg} /$ $\mathrm{kg}$, p.o.) and scopolamine hydro bromide $(0.3 \mathrm{mg} / \mathrm{kg}$, i.p.); and piracetam $(200 \mathrm{mg} / \mathrm{kg}$, i.p.) and scopolamine hydro bromide $(0.3 \mathrm{mg} / \mathrm{kg}$, i.p.) 60 and $45 \mathrm{~min}$ respectively, before the acquisition trials conducted on four consecutive days (from day 1 to day 4). In all the above mentioned groups, $0.9 \% \mathrm{w} / \mathrm{v}$ sodium chloride solution $(10 \mathrm{ml} / \mathrm{kg}$, i.p.) was administered 45 minutes before retrieval trial conducted on day 5 .

\section{Estimation of Oxidative Stress Markers in Brain Homogenate}

On day 5 immediately after behavioural testing (retrieval), rat was euthanized by overdose of $2.5 \%$ thiopental sodium $(100 \mathrm{mg} / \mathrm{kg}$, i. p.). It produced rapid induction with minimum excitation. The whole brain was carefully removed from the skull. For preparation of brain homogenate, the fresh whole brain was weighed and transferred to a glass homogenizer and homogenized in an ice bath after adding 10 volumes of phosphate buffer $(\mathrm{pH} 8,0.1 \mathrm{M})$. The homogenate was centrifuged using refrigerated centrifuge at $3000 \mathrm{rpm}$ for $10 \mathrm{~min}$ at $4{ }^{\circ} \mathrm{C}$. Drug induced lipid per-oxidation was measured by estimation of the content of MDA, nitrite, GSH, and AChE in brain blood sample of the rats. The determination was done by precipitating the protein substance using trichloroacetic acid $(10 \% \mathrm{w} / \mathrm{v})$, the protein free sample used for estimation of lipid per-oxidation parameters as follows:

\section{Protocol for the estimation of brain malondialdehyde (MDA)}

MDA was formed as an end product of lipid per-oxidation, which reacts with thiobarbituric acid and forms faint pink coloured trimethene complex. $1 \mathrm{ml}$ of supernatant was taken. $0.5 \mathrm{ml}$ of $30 \%$ of Trichloro acetic acid (TCA) and $0.3 \mathrm{ml}$ of $0.8 \%$ 
of thiobarbituric acid (TBA) were added in test tubes. The tubes were covered by the aluminum foil and then heated in water bath at $90{ }^{\circ} \mathrm{C}$ for $15 \mathrm{~min}$. Then the mixture was kept in ice cool water for $30 \mathrm{~min}$. After cooling, the absorbance of the colour supernatant in $1 \mathrm{ml}$ butanol was measured at $532 \mathrm{~nm}$ using UV spectrophotometer [25]. MDA level was expressed in $\mu \mathrm{M} / \mathrm{mg}$.

\section{Protocol for the estimation of brain Nitrite}

The accumulation of nitrite in the supernatant, an indicator of the production of nitric oxide, was determined by a colorimetric assay with the Griess reagent $0.1 \% \mathrm{~N}-(1-$ napththyl) ethylenediamine dihydrochloride, $1 \%$ sulfanilamide and 5\% phosphoric acid). Equal volumes of the supernatant and the Griess reagent were mixed and incubated for $10 \mathrm{~min}$ at room temperature in the dark. The absorbance was taken at $542 \mathrm{~nm}$ using a spectrophotometer. The concentration of nitrite in the supernatant was determined from a sodium nitrite standard curve [26].

\section{Protocol for the estimation of brain reduced glutathione (GSH)}

GSH was estimated by colorimetric method. GSH level was expressed in $\mu \mathrm{M} / \mathrm{mg}$ of protein. The assay contained $1 \mathrm{ml}$ supernatant and $1 \mathrm{ml}$ of $10 \%$ of TCA. This mixture was centrifuged for $10 \mathrm{~min}$ at 3000-4000 gyrations. Again the supernatant was collected and $10 \mu \mathrm{l}$ of supernatant, $2 \mathrm{ml}$ of $0.1 \mathrm{M}$ phosphate buffer (pH-7.4), 0.5ml of DTNB (5, 5'-dithio-bis 2-nitrobenzoic acid) and $0.4 \mathrm{ml}$ of distilled water were added and mixed. Absorbance of this mixture was measured at $412 \mathrm{~nm}$ within 15 minutes [27].

\section{Protocol for the estimation of brain AChE activity}

The resultant cloudy supernatant liquid was used for the estimation of brain AChE activity. The whole brain AChE activity was expressed in $\mu \mathrm{M} / \mathrm{min} / \mathrm{mg}$ of protein [28]. The end point was the formation of the yellow colour because of the reaction of thiocholine with dithiobisnitrobenzoate (DTNB) ions. The rate of formation of thiocholine from acetylcholine iodide in the presence of tissue cholinesterase was measured using spectrophotometer. The resulting yellow colour was due to reduction of DTNB by certain substances in the brain homogenate and due to non-enzymatic hydrolysis of substrate. After having calibrated the instrument, the change in absorbance per min of sample was read at $412 \mathrm{~nm}$. The rate of hydrolysis of substrate was calculated using following formula:

\section{$\mathrm{R}=$ change in absorbance $/ \min \times 5.74 \times 10^{-4} / \mathrm{Co}$}

Where, $\mathrm{R}=$ rate of hydrolysis of acetylcholine iodide $/ \mathrm{min} / \mathrm{mg}$ tissue, $\mathrm{C} 0=$ weight of tissue homogenate in $\mathrm{mg} / \mathrm{mL}$.

\section{Statistical analysis}

All the results were expressed as Mean \pm S.E.M. Data were analyzed by analysis of variance (ANOVA) followed by Turkey's test, Dennett's t test and student's and column static post-hoc tests using Graph Pad prism, version 5.03. The $\mathrm{p}<0.05$ was considered as statistically significant.

\section{Results and Discussion}

Effect of CMEBOB on scopolamine and age induced changes in ELT during acquisition trials using Morris water maze model

Chloroform methanolic extract of Brassica oleracea L. var. botrytis (СМЕВOB) flowers was investigated for its neuroprotective effect on scopolamine and age induced memory deficits using Morris water maze test. Scopolamine hydro bromide was administered in rats $30 \mathrm{~min}$ before acquisition trials conducted on four consecutive days (day 1 to day 4) and ELT was noted as an index of acquisition and learning. Indeed, blockade of central muscarinic receptors could induce a pattern of cognitive impairment even in young rats. Scopolamine actions are limited to the blockade of brain function mediated via $\mathrm{M}_{1}$ muscarinic cholinergic receptors.

Chloroform methanol extract of the plant drug was administered at $2000 \mathrm{mg} / \mathrm{kg}$, p. o. and $3000 \mathrm{mg} / \mathrm{kg}$, p. o. doses in rats. The ELT of CMEBOB flowers extract, conducted on four consecutive days are shown (Table 1). It is noted that the scopolamine and age have a significantly increasing effect on ELT. Chloroform methanolic extract of the plant drug and piracetam have a decreasing effect. Each value of escape latency time (ELT) is a mean value of four consecutive acquisition trials conducted from day 1 to day 4 with a gap of 5 minutes. Results were given in mean \pm S.E.M $n=6$ in each group. $a=p<0.05$ versus day 1 ELT in control group; $b=p<0.05$ versus ELT in control group on respective day, $\mathrm{c}=\mathrm{p}<0.05$ versus ELT in scopolamine treated group and $\mathrm{d}=\mathrm{p}<0.05$ versus ELT of aged rats. One way ANOVA followed by Turkey's multiple range tests.

A marked decrease in ELT of control group's rat during ongoing acquisition trials denotes normal acquisition of memory and an increase in time spent in target quadrant (Q1) in comparison with other (Q2, Q3 \& Q4) quadrants to search missing platform during retrieval trial indicates retrieval of memory. No effect of normal saline solution employed in the present study to prepare solutions of drugs has been noted on acquisition and retrieval of memory. Therefore, the effect of pharmacological intervention on acquisition and retrieval trial of memory is due to plant drug and not because of its vehicle.

Effect of СМЕВОВ on scopolamine and age induced changes in time spent in target Quadrant (TSTQ) during retrieval trial using Morris water maze model

The effect of СМЕВОВ flowers extract at dose of 2000 \& $3000 \mathrm{mg} / \mathrm{Kg}$ was observed against scopolamine and age induced memory deficits in MWM. The TSTQ was assessed to evaluate the retrieval of memory during retrieval trial conducted on day 5. The plant drug showed protection against scopolamine and age induced memory deficits in rats (Table 2).

The effect of the administration of chloroform: methanol extract of Brassica oleracea flowers (CMEBOB) on time spent by rat in quadrant(s) during retrieval trial is exhibited. The 
time spent in quadrant (s) for control, vehicle (saline solution), standard drug (Piracetam), amnestic agent (scopolamine and age) and plant drug (CMEBOB) are shown. Note that while the amnestic agent and aged rats have a significantly decreasing effect on time spent in target quadrant (Q4), the standard and plant drug have a reversing effect. Each value represents mean time spent in quadrant (s) +S.E.M. $a=p<0.05$ Vs time spent in target quadrant (TSTQ) in control; $b=p<0.05$ Vs time spent in target quadrant (TSTQ) in scopolamine; $\mathrm{c}=\mathrm{p}<0.05 \mathrm{Vs}$ time spent in target quadrant (TSTQ) in aged rats.

\section{Effect of CMEBOB per se on TLT as inflation ratio of young and aged rats}

The effect of CMEBOB flowers extract per se on TLT at doses of $2000 \mathrm{mg} / \mathrm{kg}$, p.o. and $3000 \mathrm{mg} / \mathrm{kg}$, p.o. was observed against ageing related and scopolamine induced memory deficits in rats using elevated plus maze test. The dose dependent increase in the inflation ratio by СМЕВОВ flowers extract has proved that the plant possessed neuroprotective effect (Table 3). On the basis of results it can be concluded that CMEBOB flowers extract improves learning and memory. Thus, $\mathrm{CMEBOB}$ extract meets a major criterion for no tropic activity, namely, improvement of memory in absence of cognitive deficit. This observation has been strengthened by the finding that Brassica oleracea has increased the TLT as inflation ratio like piracetam indicating restoration of memory function [29].

\section{Effect of CMEBOB on ageing related and scopolamine induced changes in TLT as inflation ratio}

Chronic administration of cauliflower $(2000$ and 3000mg/ $\mathrm{kg} /$ day for 4 days) significantly increased TLT as inflation ratio reversed ageing related and scopolamine-induced memory deficits in rats indicating improvement learning and memory (Table 3). The effect of chronic administration of chloroformmethanolic flowers extract of Brassica oleracea L. var. botrytis (CMEBOB) on transfer latency time (TLT) of rats is exhibited. The TLT for control, vehicle (saline solution), standard drug (Piracetam), memory deficits agent (scopolamine), aged rats and plant drug (СMEBOB) are shown.

Note that while the amnesic agent and aged rats have a significantly decreasing effect on TLT as inflation ratio, the standard and plant drug have a reverse effect. Results were expressed in means \pm S.E.M with $n=6$ in each group. $a=p<0.05$ versus TLT of control group and $b=p<0.05$ versus TLT of scopolamine treated group and $\mathrm{c}=\mathrm{p}<0.05$ versus TLT of aged rats, one way ANOVA followed by Turkey's multiple range test.

The in-vivo study of Brassica oleracea L. var. botrytis was further supported by the estimation of biochemical parameter like brain AChE activity, GSH, MDA and NO estimations. Oxidative stress biomarkers (elevated brain AChE, MDA, nitrite, catalase and lower GSH and SOD levels) in age related and scopolamine induced memory deficit in rats were significantly reversed by the flowers extract (Table 4). Effect of Brassica oleracea
L. var. botrytis on oxidative stress biomarkers in rat's brain homogenates was estimated spectrphotometrically.

As compared to control group in ageing and scopolamine treated group significant increase in AChE, MDA, NO and catalase levels but decrease in GSH, SOD levels were noted. Piracetam, Brassica oleracea L. var. botrytis (2000 and $3000 \mathrm{mg} / \mathrm{Kg}$, p. o.) treated aged group reduced the AChE, MDA, NO activity but increased GSH and SOD levels. AChE in $\mathrm{M} / \mathrm{min} / \mathrm{mg}, \mathrm{MDA}, \mathrm{GSH}$, NO in $\mathrm{M} / \mathrm{mg}$, catalase in $\mathrm{mg} / \mathrm{min} / \mathrm{mg}$ and SOD level in Units $/ \mathrm{mg}$ of protein were expressed. Coulomb static was followed.

Suloraphane, an isothiocynate sulfur containing component of the flowers is long lasting antioxidant and detoxifier, has been shown to stop over-rapid ageing by restoring antioxidant gene expression in human epithelial and promoting body's immune defense system. The evidence of cauliflower antioxidant properties may either prevent or delay chronic diseases associated with ageing [30]. СМЕВОВ flowers extract significantly reversed ageing related and scopolamine induced memory deficit in rats. Cauliflower is rich in tryptophan (precursor of serotonin) and choline, which may boost brain.

Choline exhibits cytoprotective and neuroprotective actions in-vivo and in-vitro. Cauliflower is reported to increase the formation and release of serotonin, choline and in brain and has allicin, potent antioxidant glycosides, fatty acid, cellulose, volatile oil, steroids, napthoquinone, vitamin-K, anti-inflammatory, immunostimulant and detoxification effects. Unique nutrition profile of cauliflower implies that it increases the resistance of the body against any onslaught. The underlying mechanism of neuro-protection may be attributed to its AChE inhibiting activity, anti-oxidant property, presence of tryptophan, cholineallic in and suloraphane.

\section{Conclusion}

Dementia accompanying ageing causes an obvious decline in the quality of life. Decreased levels of serotonin and choline in the brain have been reported to induce memory deficits and dementia due to increase in oxidative stress and AChE activity. Aged animals showed impaired learning and memory. Scopolamine $(0.3 \mathrm{mg} / \mathrm{kg}$, i.p.) is a central anti-cholinergic drug that blocks muscarinic cholinergic receptors, consequently impairs acquisition and retrieval of memory along with reduced cerebral blood flow [31].

Chronic administration of chloroform: methanol (2:1) extract of Brassica oleracea L. var. botrytis flowers improved learning and memory, prevented age related and scopolamine induced experimental memory deficits in rats by inhibiting acetyl cholinesterase mediated hydrolysis of acetylcholine and oxidative stress as reflected by significantly increase in TLT as inflation ratio in EPM, decrease in ELT on four consecutive acquisition days and increase in TSTQ on day 5 in MWM respectively as compared to aged rats and scopolamine treated group. 
Drugs that inhibit AChE enzyme, protect acetylcholine from hydrolysis and may increase the level of acetylcholine neurotransmitters in hippocampus region of the brain and have no tropic activity [32,33]. The neuroprotective effect of Brassica oleracea L. var. botrytis flowers on memory deficits of aged and young rats may be attributed to its potential serotonin and cholinergic, anti-oxidative, anti-cholinesterase activity and could be useful as memory-restorative agent in treatment of clinical dementia of young and elder individuals.

\section{References}

1. Dua JS, Prasad DN, Tripathi AC, Gupta R (2009) Role of traditional medicine in neuropsycho pharmacology Asian Journal of Pharmaceutical and Clinical Research 2(2): 72-76.

2. Harrison NL, Lange GD, Barker JL (1998) Pre and post synaptic aspects of GABA-mediated syneptic inhibition in cultured cell hippocampal neurons. Adv Biochem Psychopharmacol 45: 73-85.

3. Lanzino G, Lanzino DJ, Wang D (2002) cerebro vascular disease and cognitive dysfunction. Neurol Res 24(4): 331-336.

4. Howlett DR, Simmons L, Dingwall Christie G (2000) In search of an enzyme: the $\beta$-secretes of Alzheimer's disease is an aspartic proteinase Review 23: 565-570.

5. Brucki SMD, Ferraz AC, R. de Freitas G, Massaro AR, Radanovic M, et al. (2011) Treatment of vascular dementia. Dement Neuropsychol 5(4): 275-287.

6. Tripathi K D (2013) Essentials of Medical Pharmacology. (7th edn) J. P. Brothers Medical Publishers (P) LTD, New Delhi, India, 425-491.

7. Tosato M, Zamboni V, Ferrini A, Cesari M (2007) The aging process and potential interventions to extend life expectancy. Clin Interv Aging 2: 401-412.

8. Tandon S (2006) "Oxidative stress, Ageing and Indian Medicinal Plants." Current R \& D Highlights 11.

9. Ritchie K, Kildea D (1995) Is senile dementia "age-related" or "ageingrelated"? Evidence from meta-analysis of dementia prevalence in the oldest old. Lancet 346(8980): 931-934.

10. Aevarsson O, Skoog I (1996) A population based study on the incidence of dementia disorders between 85 and 88 years of age. Journal of the American Geriatrics Society 44(12): 1455-1460.

11. Glick S D, Zimmer berg B (1972) The amnesic effect of scopolamine. Behav Biol 7(2): 245-254.

12. Akhondzadeh S, Noroozian M, Mohammadi M, Ohadinia S, and Jamshidi AH, et al. (2003) Saliva officinalis extract in the treatment of patients with mild to moderate Alzheimer's disease: a double blind, randomized and placebo controlled trial. J Clin Pharm Ther 28(1): 53 59.

13. Kamboj VP (2000) Herbal Medicine. Current Science 78: 35-39.

14. Kyung SS (2006) Anti-dementia agents from natural products. In Development and Applications of Bioactive Materials' $89^{\text {th }}$ International Symposium of Korean Society for Applied Biological Chemistry 66-67.

15. Khare C P (2007) Indian Medicinal Plant reprints. Springer New Delhi 267.
16. Ashraf M, O’Leary JW, Mehmood S (1990) Response of four Brassica species to drought stress. Envir Exp Bot 30: 93-100.

17. Boulougouris V, Glennon JC, Robbins TW (2008) Dissociable effects of selective 5-HT2A and 5- HT2C receptor antagonists on serial spatial reversal learning in rats. Neuropsychopharmacology 33(8): 20072019.

18. Ong ES (2004) Extraction methods and chemical standardization of botanicals and herbal preparations. J Chromatogr B Analyt Technol Biomed Life Sci 812(1-2): 23-33.

19. Shiotsuki H, Yoshimi K, Shimo Y, Funayama M, Takamatsu Y, et al. (2010) A rota-rod test for evaluation of motor skill learning. J Neurosci Methods 189(2): 180-185.

20. Ashwlayan VD, Antal S (2016) Normal changes: associated with ageing in human being Published in International Journal of Medical Research and Pharmaceutical Sciences 3(5):44-56.

21. Safer DJ, Allen RP (1971) The central effects of scopolamine in man Biol Psychiatry 3(4): 347-355.

22. Parle M, Singh N (2014) Animal models for testing memory. Asia Pac J Pharmacol 16: 101-120.

23. Hampson RE, Rogers G, Lynch G, Deadwyler SA (1998) Facilitative effects of the ampakine CX516 on short- term memory in rats: correlations with hippocampal neuronal activity. An Article of J Neurosci 18(7): 2748-2763.

24. Morris R (1984) Developments of water maze producer of studying spatial learning in the rats. J Neurosci Meth 11(1): 47-60.

25. Okhawa H, Ohishi N, Yagi K (1979) Assay for lipid per-oxidation in animal tissue by thiobarbituric acid reaction. Anal Biochem 95(2): 351-358.

26. Green LC, Wagner DA, Glogowski J, Skipper PL, Wishnok JS, et al. (1982) Analysis of nitrate nitrite and nitrate in biological fluids. Anal Biochem 126(1): 131-138.

27. Anderson ME (1985) Determination of glutathione and glutathione disulfide in biological samples. Methods Enzymol 113: 548-555.

28. Ellman GL, Courtney KD, Andres V JR, Feather-Stone RM (1961) A new and rapid colorimetric determination of acetylcholinesterase activity. Biochem Pharmacol 7: 88-95.

29. Madhukar A, Ashwlayan VD (2017) Antidementic activity of Brasicca olarecae L. (Brassicaceae) on memory deficits in young male rats. Published in Pharmacy Pharmacology International Journal 5 (3): 1-9.

30. Grottick AJ, Higgins GA (2002) Assessing a vigilance decrement in aged rats: effects of pre-feeding, task manipulation, and psycho stimulants. Psychopharmacology (Berl). 164(1): 33-41.

31. Kulkarni SK, Kasture SB, Mengi SA (2010) Efficacy study of Prunus amygdalus (almond) nuts in scopolamine-induced amnesia in rats. Indian J Pharmacol 42(3): 168-173.

32. Kopelman MD (2002) Disorders of memory. Brain 125 10(1): 21522190.

33. Kumar A, Dogra S, Prakash A (2009) Neuroprotective effects of Centella asiatica against intracerebroventricular colchicine-induced cognitive impairment and oxidative stress. Int J Alzheimers Dis 1-8. 
This work is licensed under Creative

Commons Attribution 4.0 License

DOI:_10.19080/GJPPS.2017.03.555620

\section{Your next submission with Juniper Publishers will reach you the below assets}

- Quality Editorial service

- Swift Peer Review

- Reprints availability

- E-prints Service

- Manuscript Podcast for convenient understanding

- Global attainment for your research

- Manuscript accessibility in different formats

( Pdf, E-pub, Full Text, Audio)

- Unceasing customer service

Track the below URL for one-step submission https://juniperpublishers.com/online-submission.php 